\title{
Title: A theoretical foundation for the ethical distribution of authorship in multidisciplinary publications
}

Elise Smith, MA, PhD Candidate (elise.smith@umontreal.ca)

Applied Social Sciences, Bioethics Programmes, University of Montreal

Public Health Research Institute of the University of Montreal

Montreal, Canada

\begin{abstract}
In academia, authorship on publications confers merit as well as responsibility. The respective disciplines adhere to their "typical" authorship practices: individuals may be named in alphabetical order (e.g. in economics, mathematics), ranked in decreasing level of contribution (e.g. biomedical sciences) or the leadership role may be listed last (e.g. laboratory sciences). However, there is no specific, generally accepted guidance regarding authorship distribution in multidisciplinary teams, something that can lead to significant tensions and even conflict. Using Scanlon's Contractualism as a basis, I propose a conceptual foundation for the ethical distribution of authorship in multidisciplinary teams; it features four relevant principles: desert, just recognition, transparency and collegiality. These principles can serve in the development of a practical framework to support ethical and non-arbitrary authorship distribution, which hopefully would help reduce confusion and conflict, promote agreement and contribute to synergy in multidisciplinary collaborative research.
\end{abstract}




\section{INTRODUCTION}

In 1953, James Watson and Francis Crick were named as the authors of the publication "Molecular Structure of Nucleic Acids; a Structure for Deoxyribose Nucleic Acid" in the journal Nature (Watson and Crick 1953). While historians have debated the relevance and importance of various discoveries in molecular science (de Chadarevian 2002; Abir-Am and Elliott 2000), there is little dispute as to the major significance of the discovery of the doublehelix structure of deoxyribose nucleic acid (DNA). But what of Rosalind Franklin? There is little mention in science manuals of the contribution of the biophysicist Rosalind Franklin to the discovery of the structure of DNA. Watson has admitted that he used Franklin's unpublished experimental work without her knowledge, including her measurement of the repeating DNA unit and X-ray diffraction data showing the helical structure (Maddox 2003). While Watson and Crick were named on the paper, and later received the Nobel prize with a contributing colleague Maurice Wilkins, Franklin's name was absent. If authorship practices at the time had recognized everyone who had substantially contributed to the research, perhaps science history would tell a different story. One can only wonder how Rosalind Franklin's career would have progressed had her contribution been acknowledged. Would she have had more support leading to more scientific discoveries that could have shaped science in a different manner?

The expression "publish or perish" is an imperative in most disciplines, from the humanities and social sciences to the fundamental sciences, the health sciences and other applied sciences (Clapham 2005; Beasley 2005; De Rond and Miller 2005; van Dalen and Henkens 2012). Authorship of published works is considered an increasingly important reward in the contemporary system of science (Latour 1989; Latour and Woolgar 1979). A researcher's record of publication is a key criterion in the hiring, promotion, and tenure of researchers and professors, and a central consideration in deliberations to award grants, contracts, fellowships and prizes (Shamoo and Resnik 2009).

Issues surrounding authorship - i.e., who should be named an author, in what order, based on what contribution, and with what responsibility - have increased in number and complexity with the significant growth of collaborative research, especially when it involves contributors from different disciplines, countries, and cultures. Unlike the relatively small team that discovered the structure of DNA in 1953, contemporary team research may include hundreds of members who may be named as authors on a publication. For example, in genetics/genomics research, large teams are the norm; the study of "The Complete Genome Sequence of the Gram-Positive Bacterium Bacillus Subtilis" (Kunst et al. 1997) had 151 authors, albeit an unusually large number for this field. While team research has become commonplace in the natural sciences, it has also achieved greater prominence in the social sciences where relatively smaller collaborative models now account for over half of research projects (Endersby 1996; Gingras and Archambault 2006). Collaborative practices in the humanities occur to a much lesser extent, with only $10 \%$ of papers being collaborative; the remaining 90\% are sole authored publications (Gingras and Archambault 2006).

This transition from sole authorship to multi-authorship reflects the evolution toward strategies of collaborative research that are broader in scope and centered on addressing complex problems that require the competencies of researchers from many disciplines. An individual researcher who shuns multidisciplinary collaboration and attempts to "go it alone" without the necessary expertise and knowledge from other highly specialized (sub)fields may face the daunting prospect of falling short, i.e., being seen as a "jack-of-all-trades and master of 
none". As a result, new or "hybrid research fields" have been created by integrating knowledge from multiple disciplines (Barkovic 2010, p.954). For example, women's studies draws upon the contributions of scholars from political science, sociology, philosophy and history; and High Energy physics may involve scholars specializing in condensed-matter physics, the life sciences, material science, chemistry, and nano-science. ${ }^{1}$

For team members, the order of authorship may be critical, especially when it ranks the contribution of individuals and as such, bestows more or less prestige and responsibility. Disciplines such as psychology or computer sciences often list individuals in decreasing order of importance of contribution (Bennett and Taylor 2003). But, to distribute authorship in this manner, the team must distinguish whose work is more valuable and merits higher ranking. This is not an easy task, especially when the nature or types of contributions vary (e.g., intellectual, technical). In laboratory based sciences and in large biomedical teams, individuals may be named in decreasing order of importance of contribution and importance may be attributed to the last author as Principal investigator; this underscores one's leadership role in obtaining funding or grants, managing a research laboratory or mentoring students. In disciplines such as sociology, economics and mathematics, authors are often named in alphabetical order (Van Praag and Van Praag 2008); this approach might seem more egalitarian but it fails to indicate and thus recognize the nature, extent and relative importance of the various authors' contributions within a team. Further, while particular authorship distribution practices may be considered "the norm" in certain disciplines (i.e., obvious to all members of the discipline), they may be totally opaque or completely foreign to researchers from other disciplines. The differing meanings and values inherent in the authorship norms of various disciplines can be confusing and even contradictory. This can give rise to disputes and ethical challenges when determining authorship. What may be valued and considered an appropriate and acceptable authorship practice in one disciplinary culture may be considered unimportant, unworthy of authorship, or even unethical in another discipline.

The term "multidisciplinary research" is defined here as all research that includes more than one discipline; several different types of multidisciplinary research (e.g., interdisciplinary, cross-disciplinary, trans-disciplinary) have been the topic of much scholarly discussion (Sulmasy and Sugarman 2010), but these distinctions are beyond the scope of this paper. The co-existence of multiple authorship practices and disciplinary norms, and the likelihood of significant disputes around authorship distribution, makes multidisciplinary teams an apt context in which to investigate what could constitute basic principles of ethical authorship. This is not to say that authorship issues are not present in disciplinary contexts; nor is it to say that the authorship orders used in different disciplines are inherently right or wrong, but rather that there is greater disagreement and discord when different norms conflict in authorship decisions. These disagreements in multidisciplinary teams (especially in health based sciences) have created much debate in recent years, which gives impetus to continued reflection, and perhaps even to means of changing guidance and behavior.

In this paper, I present a theoretical approach - inspired by Scanlon's theory of contractualism as presented in his book What We Owe Each Other (Scanlon 1998) - as a foundation for elaborating methods for fair or ethical authorship distribution, and in particular,

\footnotetext{
${ }^{1}$ In this article, I define "discipline" quite broadly as an institutionalized and recognized set of knowledge, approaches and/or methods used towards the evolution of science. I am aware that the definition of "discipline" has been a debate for quite some time in the philosophy of science, but this debate is outside the scope of the paper.
} 
for decisions regarding the order of authors of multi-authored multidisciplinary academic publications. I begin by providing a brief background section that includes an overview of the relevant literature on authorship collaboration to shed light on important contextual elements and also to underscore the lack of theoretically grounded guidance for authorship distribution (mainly with regards to authorship order). I then show how Scanlon's contractualism, and the application of certain ethical concepts - such as specific interpretations of desert, just recognition, transparency and collegiality - can contribute to a sound theoretical foundation for the development of an eventual practical framework (which is beyond the scope of this paper) to support ethical and non-arbitrary authorship distribution in multidisciplinary team publications.

\section{BACKGROUND}

\section{Authorship and Collaboration in Science}

The emphasis on collaboration in science started during the Big Science era after World War II (Cronin 2005; Katz and Martin 1997). Governments recognized the benefits of investing massively in science; projects became significantly bigger and more complex, necessitating more diverse expertise and greater collaboration (McClellan and Dorn 1999). This extended beyond the familiar, traditional model of scientific inquiry as a solitary endeavor. While it may be argued that throughout history, some degree of collaboration has existed among researchers through the exchange of ideas, the sharing of methods and cooperation with technical laboratory assistants (Biagioli 1999), one or very few individuals were considered authors. In contemporary science, researchers collaborate as members of a team where tasks and responsibilities are assigned, and ultimately acknowledged or reflected in multi-authored published works.

While definitions of scientific authorship may differ to some extent, there is general agreement in the literature as well as in academic practice, that individuals who "contribute substantially" to a research project merit some level of authorship (Louis et al. 2008). However, the term, "substantial contribution" remains vague and largely undefined (Smith and WilliamsJones 2011). In some fields, especially in biomedical sciences, individuals might also need to participate in the critical revision or drafting of the manuscript and give final approval of the manuscript. While an increased number of collaborators may indeed indicate more contribution (because of more labor intensive projects), this may not necessarily be the case. Individuals might simply be contributing to different projects in smaller amounts and they could seek to bolster the quantity of their published works without in fact contributing or collaborating more to the general scientific enterprise.

In the scholarly literature about authorship, there has been considerable interest in practices that do not respect the concept of "substantial contribution". For example, "guest", "gift", "unjustified" and "honorary" authorship broadly include naming an individual as an author when they did not substantially contribute to the research, thus receiving undeserved credit and recognition (Ross et al. 2008; Street et al. 2010; B. Moffatt 2011). Conversely, "ghost" authorship - the omission of an individual who has contributed substantially to a study - has also been discussed as an important ethical issue in the authorship literature (Anstey 2014; Matías-Guiu and García-Ramos 2011; Mowatt et al. 2002), especially in university-industry relations with the pharmaceutical sector (Sismondo 2009; Barton Moffatt and Elliott 2007; 
Lexchin et al. 2003). In order to hide financial conflict of interests, individuals working for or being paid by pharmaceutical companies may refuse authorship (becoming a 'ghost author') and assign authorship to another individual or team (likely from the no-profit sector i.e. a university) to eliminate any concerns or doubts about bias in research.

Empirical studies of researcher self-reporting of behavior (e.g., surveys, interviews) show alarming rates of authorship issues. For example, Flanagin and colleagues surveyed corresponding authors who reported honorary authorship, ghost authorship, or both, and found that these were present in $21 \%$ of medical articles (Wislar et al. 2011). Mowatt and colleagues surveyed authors of Cochrane reviews who declared that $39 \%$ of articles have evidence of honorary authorship and 9\% have evidence of ghost authorship (Mowatt et al. 2002). By simply looking at a list of authors on a byline, a reader will be hard-pressed to know if there is guest or ghost authorship. In many cases where there is collaboration, a reader will have little idea who truly contributed to what tasks or ideas, thus creating a general "obfuscation of authorship" (Bennett and Taylor 2003). Without knowing who did what in a research group - especially in large research teams - journals, institutions and funding councils do not know who should receive credit or who should be held accountable if questionable practices like research misconduct (such as fabrication, falsification and plagiarism) have occurred. In a highly multidisciplinary team, there may actually be no one individual who can vouch for the project as a whole because of the necessity of so many different specializations. Further, if authorship is seen in its traditional mode as being an individual who is accountable for the project as a whole, the highly multidisciplinary project could even be construed as "authorless" (Kukla 2012).

This obfuscation of authorship has led to confusion and much debate, especially in the biomedical sciences. Consequently, a series of propositions were suggested as ways to replace authorship. For example, "corporate authorship" has been proposed where the team or group name may take precedence over the names of individual contributors in the byline, as in the case of the GUSTO team research (GUSTO 1993). ${ }^{2}$ However, this last option is rarely implemented (Weeks, Wallace, and Kimberly 2004); many journals still require that individuals be named somewhere in the publication (e.g., in a footnote or endnote) to ensure a degree of individual accountability for the publication. Medical editors and scholars have argued that authorship could be replaced with contributorship (Smith 2012; Smith 1997; Rennie, Yank, and Emanuel 1997). Under this approach, individuals would be listed for their specific task(s) (e.g., study design, data collection, analysis, drafting of the manuscript), and as such, they would have a more direct link to, and accountability for, their contribution. A contributorship section has been added to a substantial number of well reputed journals (Rennie 2001). Recently in 2014, Allen and colleagues created a taxonomy to better categorize contributorship (Allen et al. 2014). However, the authorship concept has remained predominant (sometimes co-existing with contributorship), and it is still sought after as the most significant of metrics by which researchers are evaluated. The challenges in authorship distribution have not been entirely resolved by contributorship. Contributorship may augment transparency - noting who did what tasks - but it does not clarify who should receive more or less credit. As such, contributorship will not suffice to 'fix' all authorship issues.

The considerable number of authorship distribution issues has led to a growing recognition of the importance of fairly distributing authorship (Shamoo and Resnik 2009, p.69),

\footnotetext{
${ }^{2}$ More discussion of this model will be presented in the section on transparency.
} 
even if fairness remains - as I will discuss later - somewhat ill defined. There is growing awareness that unfair and misleading practices such as those mentioned above not only create doubt about "who did what" and "who is responsible for what", but can also undermine trust and confidence in the quality of the research itself and the reputation of the research community more generally. The scientific endeavor is arguably founded on trust in, and the truthfulness of its various elements, including: sound methodology, critical acumen, systematic rigor in testing and measurement, the mitigation of distortion and bias, and evidence-based findings. It stands to reason that if researchers are ready to lie about authorship, then there might be other elements within their research that are not truthful (Wager 2009).

Journal editor organizations have shown initiative and developed authorship guidelines or recommendations that are receiving attention in the literature on authorship (Tsao and Roberts 2009; Wager 2007). These guidelines or recommendations are intended to promote publication ethics and have been quite effective in stimulating dialogue about authorship issues. Three major organizations occupy center stage, each having developed their own authorship guidance or recommendations: the International Committee of Medical Journal Editors (ICMJE) (2015), the World Association of Medical Editors (WAME) (2013a), and the Committee on Publication Ethics (COPE) (2013). The most explicit and detailed authorship criteria are found in the ICMJE recommendations, which state that authorship should be based on:

1. Substantial contributions to the conception or design of the work; or the acquisition, analysis, or interpretation of data for the work; AND

2. Drafting the work or revising it critically for important intellectual content; AND

3. Final approval of the version to be published; AND

4. Agreement to be accountable for all aspects of the work in ensuring that questions related to the accuracy or integrity of any part of the work are appropriately investigated and resolved. (ICMJE 2015)

Alongside such guidance, specific journals have often remained very vague regarding authorship either referring to the guidance of a journal editor organization or simply mentioning that authors should agree on the final manuscript (Wager, 2007).

Once the criteria or qualifications for authorship have been determined and authors named, decisions must be made concerning the order of authors. The ICMJE guidelines mentions a "collective responsibility" (ICMJE 2014 p.2) to distribute authorship, which may suggest some form of democratic decision making, an approach also found in WAME documents. WAME mentions that "The authors themselves should decide the order in which authors are listed in an article" (WAME 2013b). Interestingly, the order of authorship would be the outcome of a simple agreement based on "many different criteria" (WAME 2013b). But, there is little clarity regarding relevant or acceptable criteria. COPE recommends that an authorship agreement be developed and adhered to by team members in order to foster constant communication from the outset and throughout the research process, in order to limit disputes. However, COPE does not outline the content of such an agreement.

In a self-governed system such as academia, an open and democratic forum may indeed help to mitigate disputes and conflicts among team members, but it cannot pre-empt or eliminate collusion that intentionally exploits some members or that perpetuates discriminatory practices. Further, the differing disciplinary cultures and practices of individuals in 
multidisciplinary teams can make decision-making and consensus on authorship particularly challenging. I argue that guidance should have a sufficiently inclusive and broadly accepted theoretical grounding in order to mitigate conflict or discord. This would produce decisions based on a sound and ethical rationale, rather than power relations, traditions or belief structures which may no longer be adequate.

While editor organizations (ICMJE, WAME, COPE) have definitely stimulated debate regarding authorship criteria, there is no unanimity on the subject, and discussion remains quite limited when it comes to authorship order. Also, the critique has been made that rules, like those of ICMJE, are insufficiently flexible to adapt to the different research contexts. This may be the case, a fortiori, in multidisciplinary research where the scope of the scientific inquiry is complex, and the nature and value of contributions are diverse. While scholars have mentioned the need for more discussion about authorship distribution and order (Lambert-Chan 2013), none have offered practical, detailed or ethically justified guidance. This paper will propose the theoretical foundation for the eventual development of a practical ethical framework for distributing authorship fairly.

\section{CONTRACTUALISM IN AUTHORSHIP DISTRIBUTION}

As noted in the previous section, not all agreements are ethical. Consider the arrangement where a student agrees to put her supervisor as first author on a paper in order to be in the latter's good graces, regardless of the fact that the supervisor did not contribute to the research; this is considered a form of gift authorship. So, while agreement might be one element of ethical theory, it is not in and of itself validation or proof of ethical behavior. Individuals have agreed (some more freely than others), and still do, to accept slavery, racism and sexism. I do, however, think that the dynamic or process of agreement can facilitate the development of ethical behavior, especially in a team setting. Comstock (Comstock 2013) has developed a Responsible Conduct of Research (RCR) framework that relies extensively on agreement and mentions the notion of contractualism, although he does not expand on this theory and gives little detail as to how it can guide the distribution of authorship. ${ }^{3}$ However, I agree that Comstock was heading in the right direction and so I intend to show that contractualism can indeed be effective in helping to address certain RCR issues, namely, authorship.

Different interpretations of contractualism have been at the heart of classic ethical theories such as those of Rousseau (1762) and Kant (1785), as well as a central notion in the works of contemporary philosophers such as Rawls (1971), Daniels (2000; 1990) and Scanlon (1998). The basic idea is that the ethical principles, rules or values governing our actions can be justified or deemed appropriate when they are the result of a hypothetical agreement between individuals. In the words of Darwell, "whether an action is right or wrong must depend on whether the act accords with or violates principles that are, or would be, the object of suitable agreement" (Darwell 2003, p.1). By referring to agreements as hypothetical, I follow these scholars in referring broadly to agreements to which individuals could reasonably agree. But I will focus, in this paper, on one particular version of contractualism, that of Thomas Scanlon as

\footnotetext{
${ }^{3}$ These shortcomings can be explained by the fact that Comstock's book concerns the responsible conduct of research in general. To tackle such a wide range of issues, Comstock draws upon egoism, contractualism, moral rights and utilitarian theory. Contractualism and authorship distribution are but a small portion of his work.
} 
developed in his book What We Owe Each Other (Scanlon 1998), ${ }^{4}$ and I will argue that it applies particularly well to the context of authorship distribution.

Scanlon grounds his theory on a central statement about what constitutes a wrong action, rather than defining what is right: "An act is wrong if its performance under the circumstances would be disallowed by any set of principles for the general regulation of behavior that no one could reasonably reject as a basis for informed unforced general agreement" (Scanlon 1998, p.153). By refraining from defining precisely what the right action is, Scanlon provides room to accommodate a broad range of possible right actions while still acknowledging that unethical actions or wrongness exist. At the outset of his book, Scanlon describes the primal and foundational nature of reason in normative thought. He states that reasons are propositions (e.g., judgments about empirical facts or psychological states) that count "in favor of some judgmentsensitive attitude" 5 (Scanlon 1998, p.56). As such, a reason is not an ontological element but rather a proposition with a particular status or significance that gives it normative force. Consider the expression $\mathrm{X}$ gives me reason to do $\mathrm{Y}$. This statement points to $\mathrm{X}$ as justification to act; in effect, $\mathrm{X}$, is a proposition that has normative force as it provides "good reason" as the impetus for action.

According to Scanlon's theory, values are not metaphysical or teleological. There is no absolute, universal list of values that applies systematically to every context and all circumstances. Simply put, we value those things that we have reason to consider as valuable. Depending on one's reasons, the nature and order of importance of values vary; what we value takes diverse forms, e.g., pleasure, friendship, well-being and achievement of artistic and/or intellectual excellence. Also, what is valuable in one context or at one time may not always be valued as much or at all; a value may not be seen as reasonable in certain contexts or under certain conditions. Since the circumstances of our actions often change, Scanlon points to the need to consider the context as well as the intention behind an action, or what Scanlon calls the "moral motivation" (Matravers 2003, p.4). For example, while friendship is valued in many situations in our personal life, it may seem unreasonable and inappropriate to value friendship more than actual contribution in distributing authorship in a research publication. We should thus revise the reasonableness of values on an ongoing basis according to changes in context.

According to Scanlon, it is reasonable for individuals to take into account the reasons that they, as well as others, have to justify an action. This notion of "mutual recognition" is central in that it is an acknowledgment of others as rational equals. Mutual recognition is not only important in the process of practical reasoning, it also promotes morality; we seek a moral life because we exist in relation to others and we seek to justify our reasons in a way that others cannot unreasonably reject (Scanlon 1998, p.162). There is a degree of fairness and equality inherent in the notion of mutual recognition; no one rational individual is prima facie more important than another. Agreement between equals includes the notion of reciprocity where one respects the agreement knowing that others will do the same.

When deciding whether and to what extent an act is right or wrong, we must hypothetically consider principles that are mutually recognized and relevant in the given context. As such, a principle reflects a moral rationale or reasoning in support of a specific

\footnotetext{
4 I will not consider Scanlon's earlier article entitled 'Contractualism and Utilitarianism' (Scanlon 1982) since his views changed substantially in his later work, notably by omitting reference to utilitarianism.

${ }^{5}$ For an attitude to be judgment-sensitive it must be "under the control of reason" (see Scanlon 1998 p.272).
} 
action in a given context. For example, if we acknowledge that it is important to be completely transparent about data and analysis in the verification of an experiment, we might conclude that there is sufficient reason to abide by a principle of transparency in publication, if in a given context there is no other perspective that makes this principle unreasonable. However, in the context where maintaining confidentiality and respecting the privacy of participants is paramount, the principle of transparency may not apply to the same extent or in the same manner as in the previous situation. In considering various principles, one must understand that the importance, relevance and applicability of a principle depend on the context of the action.

\section{Why use Contractualism as a Theoretical Base in Authorship Distribution?}

There are four main reasons why Scanlon's theory of contractualism applies nicely to authorship distribution:

1. It provides the necessary flexibility to adapt to the many different contexts of authorship distribution in multidisciplinary collaborations. Reasons to adopt or exclude certain principles may differ depending on team size, the nature of the research area, the disciplines involved and the geographical location of team members, to name but a few contextual factors. This form of contractualism allows us to take into consideration the values and goals that are already considered reasonable and valued in the academic community, such as: rigor, competence, trustworthiness, and knowledge development. This is an important consideration in that it allows for the subsequent development of a fair and practical framework within the existing (albeit imperfect) value system. ${ }^{6}$

2. It is useful in developing principles that allow us to challenge authorship practices that have not been questioned in a reasoned manner and that should be updated to reflect advances in authorship ethics, emerging research issues, contexts and present-day values. For example, $17^{\text {th }}$ century copyright (when the concept of authorship was born) was created to mirror existing class structures and as such, it discredited many contributors from being granted authorship (Biagioli 1999). Traditional practices that continue to enable exploitation or perpetuate unethical behavior need to be rationally and reasonably challenged and remedied.

3. The notion of mutual recognition opens the way to a fair and reasoned process wherein individuals are considered equals when making agreements and establishing principles and frameworks. This approach counterbalances to some extent the hierarchical nature and power dynamics of academia. The goal is not to eliminate hierarchy based on knowledge, which is necessary in teaching and mentoring relationships. The professor/supervisor with 'greater knowledge' necessarily occupies a position of authority and power, as she/he is responsible for evaluating and mentoring the student; this is an entirely reasonable arrangement. However, if we apply reason and mutual recognition in distributing authorship, the less powerful party (e.g., the student, research assistant, technician) should still receive equal consideration. A reasonable and acceptable agreement would take into account the viewpoints of all team members,

\footnotetext{
${ }^{6}$ As already mentioned, the development of such a framework would be the focus of future work, and thus is not presented in this paper.
} 
including students, researchers, coordinators, research assistants, and principal investigators.

4. Value is not limited to one object or element, such as well-being or utility; Scanlon considers the potential of value as a plural concept. This is particularly important and relevant in academia because of the multiple forms of value (intellectual or technical) as well as the value of reputation or the well-being of the individuals. I agree with Scanlon that many justice theories, especially those focused on the just distribution of necessary goods and services, mistakenly focus on one type of value, i.e., well-being, in measuring ethical conduct (Scanlon 1998, 110-143). While important, well-being is but one (insufficient) consideration in the scientific context, where multiple values are relevant and deserve consideration.

\section{Limitations of Contractualism in Authorship Distribution}

As with any moral theory, contractualism has its limitations and its critics, but I will limit my review of these to focus instead on the articulation of the theoretical basis for an eventual ethical authorship framework.

Briefly, Hughes and De Wije (2001) argue that the words "reasonably reject", which determine wrongness in Scanlon's theory, are too vague. However, as in any theory, a certain level of vagueness is necessary to be applicable to the many contexts and arguments in moral theory. Another important critique is the so-called aggregation problem (Hooker 2002), i.e., that the views of the greater number of individuals should have more importance than those of a few individuals or even a single person, as would argue many utilitarians (Mill 1870). To be fair, however, Scanlon's argument is built on the notion that an act is right or wrong depending on the reasonableness of the argument, and not solely on the number of individuals who make an argument. Reasonableness thus does not always result in the aggregation problem, but it remains sometimes present.

Since the focus of my work, here, is on laying the groundwork for the eventual development of an ethical authorship framework, one practical shortcoming is particularly relevant. While Scanlon's statement on contractualism is helpful in discerning wrong or unreasonable principles for the distribution of authorship, it does not tell us exactly what to do when more than one authorship distribution method and order might be reasonable to team members. In a later section on collegiality, I will discuss an approach to apply more fair procedures $^{7}$ to enable team members to agree on an ethical order of authorship in a collegial and respectful manner.

\section{DEVELOPING ETHICAL AUTHORSHIP PRINCIPLES USING CONTRACTUALISM}

In this section, I will argue that in the distribution of authorship, the specific interpretation of certain principles such as desert, equality, transparency, and collegiality can be

\footnotetext{
${ }^{7}$ I have decided to limit the discussion about procedural justice in this paper because I consider it a more practical consideration that will be better addressed once further empirical data is collected on this issue and the context of authorship distribution is better understood.
} 
considered reasonable according to Scanlon's theory. As previously stated, contractualism does not provide one best decision or outcome; but it does help us to justify or refute principles that can be used in deliberations concerning authorship distribution. Careful reflection, reflexivity (following Anthony Gidden's (1986) view of self-awareness) and practical judgment are necessary for team members to agree upon principles that meet the test of reasonableness within diverse contextual realities. Once this exercise is completed, principles can be applied in determining the selection of an authorship order. I will focus on those principles that are primary in authorship distribution and order; they do not, however, constitute an exhaustive list.

\section{Merit and Desert}

Although the words "desert" and "merit" may be used interchangeably in common parlance to talk about certain aspects of justice and responsibility - "he got what he deserved" or "she will get merit through authorship" - these are not concepts used to explain or describe fairness in philosophy or social theory. Michael Young first introduced the term "meritocracy" in his book, The Rise of Meritocracy (Young 1958), a political satire about a highly meritocratic society structured according to levels of intelligence. His dystopia, which portrayed a ridiculous and unreasonable society, was intended to persuade the British Labour government of the 1950s that the application of the principle of merit was unjust (Dench 2006). Similarly, and consistent with its roots in justice theory, contemporary political philosophy does not attribute the same importance to merit and desert that it gives to equality, equity and welfare. In liberal egalitarian philosophy, authors such as John Rawls value highly the principles of liberty and equality, while libertarians such as Robert Nozick or Milton Friedman have favored entitlement theory based on the respect of individual rights (Olsaretti 2003). According to Lewis, merit is refuted on the basis that it creates social differentiation that is commonly rejected as unjust (Lewis 1998).

Rawls' theory of justice does not define individuals as responsible for or deserving of the native endowments which they receive in life. As Rawls notes:

It seems to be one of the fixed points of our considered judgments that no one deserves his place in the distribution of native endowments, any more than one deserves one's initial starting place in society. The assertion that a man deserves the superior character that enables him to make the effort to cultivate his abilities is equally problematic; for his character depends in large part upon fortunate family and social circumstance for which he can claim no credit (Rawls 1971, p.104).

Even the willingness to make an effort, to try and so to be deserving in the ordinary sense is itself dependent in practice upon family and social circumstances. This underscores the skepticism about responsibility and free will in contemporary justice theory (in political philosophy) and has undermined any recourse to desert and merit (Pojman and McLeod 1999). But the disregard or dismissal of desert, merit and even responsibility-based arguments is at odds with many areas of ethics (e.g., professional ethics or organizational ethics) where responsibility is a key principle. It is important to note that political philosophers have largely focused on distributive justice to create fair institutions. And while I initially thought that fair distribution of authorship would be comparable to fair distribution in political philosophy, I have subsequently come to a different conclusion. 
If we focus on the context of authorship distribution for multidisciplinary research, it is reasonable to acknowledge that a theoretical foundation with different principles is warranted and that the goal of "fairness" still applies. Concepts of desert and merit can, I argue, reasonably apply in a team setting that is already institutionalized. Academic institutions have specific tasks and obligations that involve a complex mix of professional ethics, organizational ethics and justice. While notions of need and welfare linked to primary rights (such as the right to life, nourishment, etc.) found in justice theories are not the central principles or goals of academic institutions or in team research, fairness in team dynamics is nonetheless important. While I agree with many political philosophers that equity, equality and welfare are key principles in distributing essential primary goods or rights, desert may be more relevant and reasonable as a principle underlying fairness in the academic context.

In discussing authorship, I will thus use Louis Pojman's (1999) definitions of merit and desert. Pojman describes merit as "any feature or quality that is the basis for distributing positive attributions as praise, rewards and prizes" (Pojman 1999, p.86). This quality may be a natural endowment such as beauty, strength or intelligence. For example, a professor may merit tenure because of her brilliance; even though she may have achieved an excellent publication record with relative ease or less effort than other colleagues, she still merits her reward or career advancement. "Desert on the other hand is typically or paradigmatically connected with action, since it rests on what we voluntarily do or produce. It is typically connected with intention or effort" (Pojman 1999, p.86). A professor deserves tenure, in part because of her contribution to knowledge, but also because of her engagement in teaching and mentoring, involvement with administration, etc., all of which require effort and work, even if the professor may be more adept at these acts than other colleagues. The notion of effort and work is the action base for desert in this case. To summarize, people may receive merit for things for which they have not worked, such as natural beauty, innate strength or intelligence; but it is only in cases where individuals make a choice to use their talents through action that they deserve a prize or reward.

Research involves going through the often tedious processes (e.g., experiments, data collection), alongside more creative or rewarding activities (e.g., idea generation, analysis, writing) and these are choices that individuals make. These choices result in an effort to contribute to research that confers desert whereby one deserves praise for scientific contribution. This is consistent with Scanlon's contractualist approach; he mentions that it is often the case that an individual cannot reasonably reject outcomes that are sensitive to one's choice (Scanlon 1998, p.251). Choice is a precursor to responsibility which is also important in the framework of desert. ${ }^{8}$ Although individuals may receive credit or merit through authorship, we usually only consider this merit ethical if it is deserved; that is, the individual performed an action (e.g., work) that resulted in a contribution (e.g., a scientific article). If the author has not contributed but still obtains merit through gift authorship, we consider this undeserved and in Scanlon's words, unreasonable. Accordingly, the central concept in authorship distribution is desert since merit is really a consequence or result of desert.

In the literature on desert, we find Feinberg's classic expression: "S deserves $\mathrm{X}$ by virtue of P" (Feinberg 1974, p.61). In the case of authorship distribution, S would be an individual (professor, researcher, student, technician, etc.) who participates in the research process. Since

\footnotetext{
${ }^{8}$ While in the case of authorship distribution desert may be morally justified, I am not saying that outcomes are deserved if a choice is taken in all situations. Scanlon notes that the value of choice is "conditional and relative" (Scanlon, 1998, p.262).
} 
authorship is our object of study, $X$ would be authorship with the ensuing implications regarding credit (or merit) and accountability. Finally, there must be an action (P) that makes the individual deserving of authorship. David Miller mentions that the challenge with Feinberg's account of desert is to define P more precisely because "primary desert judgments are based on performances for which the agents in question are responsible, and which we appraise either positively or negatively" (Miller 2003, p.27). What Miller calls the primary desert judgment (the $\mathrm{P}$ in Feinberg's expression) is also typically called the desert base (Feldman 1995).

As mentioned previously, authors and academic journals are increasingly adopting the notion of "substantial contribution" as a central criterion for attributing authorship (regardless of the order used). The value that we put on contribution makes this a reasonable desert base. But in determining substantial contribution, should we give more credit to the amount of work or effort, or to the quality and importance of the act for the results achieved? In other words, should individuals who work harder or exert greater effort (e.g., do more writing) deserve more credit (in the form of authorship) than others whose quantitative contribution may be less but could also be more qualitatively valuable (e.g., a key idea or technical analysis)? While there may be some rationale for acknowledging hard work, in practice, there is no plausible or reasonable way to objectively quantify or measure intellectual effort. ${ }^{9}$ As with grading student essays, or reviewing grants or article submissions, the evaluation is on the final product and not on the effort involved. While it may be harsh to say, funding or praising a hard working researcher who lacks the competence or ability to contribute to the production of valuable research results (including the development ideas, methodological innovation, analysis or results) and advance the collective body of knowledge can be considered a waste of scarce resources.

\section{Why use desert as a reasonable principle in the distribution of authorship?}

Desert can be considered a reasonable principle in the distribution of authorship for several reasons. First, desert is a reasonable and practical way to link and clarify the concepts of responsibility and credit; responsibility and merit are seen as two sides of the same coin (Rennie and Flanagin 1994). Some have argued that credit should be disregarded and that only responsibility should be considered in authorship. For example, Clement states that "journal authorship discussions should never involve the allocation of credit, a relatively easy part; instead they should focus on allocation of accountability or responsibility, a more difficult part" (Clement 2013, p.3). He is right in pointing out that responsibility deserves greater prominence in authorship attribution than it has, and that it should not be overshadowed by credit. However, the distribution of credit separately from accountability and responsibility is unreasonable since one implies the other and both are integral to authorship. If you are credited with achieving a result, you are also held accountable and responsible for that result to some degree. It is reasonable to hypothesize that the sense of responsibility and accountability for one's work can influence behavior and mitigate the occurrence of unethical or dubious practices. Since responsibility for results in a collaborative team effort is to some extent shared, then there may be a tendency for individuals to divert any blame or direct responsibility for errors or poor

\footnotetext{
${ }^{9}$ This does not mean that effort and hard work are never to be acknowledged. It simply means that they are not considered in the specifics of authorship.
} 
outcomes to other members, to the team leadership generally or to the team collectively (LaFollette 1992).

As previously mentioned, the distinction between merit and desert is that desert involves a choice. An individual researcher chooses to contribute and this decision confers a certain level of responsibility on that individual for his/her contribution to the research. Desert is based on actions that are the responsibility of the individual and excludes those elements that are solely based on natural endowment or social circumstances. This does not mean that choices are not influenced by external factors (e.g., financing, career advancement), but simply that the individual remains a free agent to a reasonable extent. It is in choosing to accept responsibility for a contribution that an individual deserves to be an author. For example, in a team project, a post-doctoral researcher chooses to participate in a research project and is responsible for data collection and analysis as well as a critical review of the final paper. If the paper is published, the post-doctoral researcher will be among the authors on the by-line. Because she was responsible for the contribution, she deserves authorship and the resulting merit (or credit). Moreover, because she was responsible for certain tasks, she remains accountable for that contribution. Since desert is based in part on individual responsibility, it confers a level of accountability that is highly valued and necessary in academia, as discussed in the RCR literature.

To promote integrity in research, it is necessary for individuals to always be responsible for their contributions; contribution and responsibility should never be separated. The notion of responsibility should not, however, be confused with stewardship or the role of "guarantor", concepts that refer to the leadership responsibility of certain individuals for the entire project, including the management of team competencies and resources (e.g., how all the pieces fit together, securing research funds) to achieve the research objectives. The role of steward, usually played by the Principal Investigator (PI), is often one of coordination, oversight, and leadership. This does diminish the responsibility of other members of the group; they are still responsible for a contribution in that they have an obligation to do specific tasks with integrity. Individuals are responsible for the quality of their own work even if they are in a large team and are not the only author named on the byline. When there are many responsible individuals, typically roles are defined such that some are assigned greater responsibility for certain tasks than others. In keeping with the notion of integrity, I will use the term responsible contribution as the desert base for authorship. Responsible contribution is the outcome of choices regarding the research project, such as the methods applied, data included or excluded, or selection of concepts.

Responsibility for contribution is used in ranking individuals and is a precursor to future credit; the one who is responsible for the most contribution is often said to deserve the most authorship (usually expressed as first or last author), and thus greater credit and accountability. This conceptual clarification of the link between credit and responsibility (illustrated in Figure 1) is necessary because in the definition of authorship, key concepts such as responsibility, accountability, merit, and credit have generally been lumped together without clarification. Establishing a clear link from responsibility to contribution at the planning stage of research would arguably help to foster a more organized, collaborative team dynamic. In using the concept of desert, I distinguish two different types of responsibility; responsibility for the contribution (or the task of research) and accountability after publication. Individuals remain accountable for their contribution because they are responsible for their contribution. The link 
between the amount of contribution and the amount of accountability and merit is only possible if the individual deserved authorship. This makes the desert principle necessary but not sufficient to this conceptual approach to understanding authorship.

Figure 1: Using desert in relation to responsibility, contribution, authorship, credit and accountability

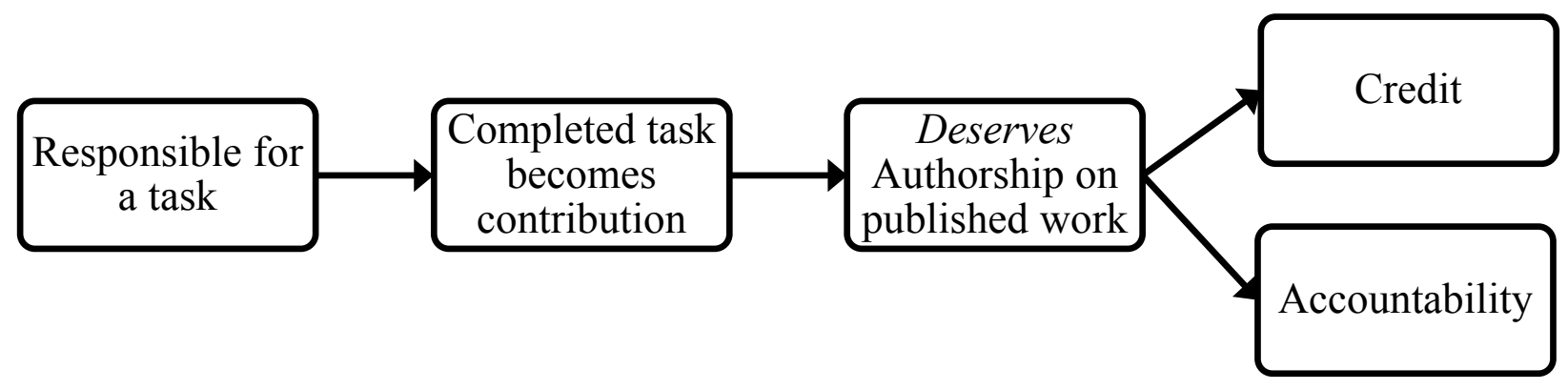

Another reason to consider desert is that it can help in determining choice of authorship order. If we state that authorship is linked to a certain amount of responsible contribution through desert, then the order could reflect this fact. If it is possible to appraise and thus differentiate contributions, one could use decreasing order of contribution to name authors. This would also be reasonable since individuals who made the 'greatest contributions' would be read first and receive the most praise; of course, this is particularly true when only the names of the first author (e.g., Smith et al.) or the first three authors (Smith, Hughes and Jones et al.) are cited in a text; this is clearly not an issue in numbered citation styles (e.g., Vancouver where no names are cited in the text). The concept of 'greatest contribution' remains vague and could be interpreted in various ways (e.g. the most cognitive change, the most labor intensive work, the most novel work). The interpretation of this notion will most likely align with the goal of the project. For example, if the goal of the research is predominantly to develop a novel method of inquiry, more value will be given to the tasks leading to this goal. Open discussion will most likely be necessary to understand the contributions of each individual (this will be discussed in greater length in the section on collegiality).

When many individuals contribute equally, they are said to deserve equal authorship. However, there can only be one first author on the byline (excluding alternate and non-standard presentation formats such as printing names in a circle or adding equal signs between authors (e.g., Mullen $=$ Kochan $=$ Kochan $=$ Mullan 2001 $)^{10}$. In such cases we can use alphabetical order and then state clearly that all individuals contributed equally, e.g., in a note directly under the author list, or in a footnote, although these options also have their limitations (as we will see in the section on transparency). Transparency becomes increasingly important in such cases and thus is also considered as a necessary principle in the distribution of authorship.

A model that includes the notion of desert can serve as an effective appraisal mechanism in the ranking of authors. The desert base, which in authorship is responsible contribution, is, if not completely quantifiable, at least comparable and may also be valued in relation to the body

${ }^{10}$ According to the authors, the equal sign $(=)$ between author names promotes equity between authors. 
of work or the project as a whole. For example, in a coded interview-based analysis where the interview process is of critical importance to the project as a whole - even more than the initial drafting of the paper - that process should be given higher value and weighted accordingly. In work of a conceptual nature, the contribution of a novel idea and its elaboration through articulation in the written text would be more heavily weighted or valued. Ultimately, we would compare the contribution of individuals relative to one another as well as relative to the project as a whole. Since only the desert base (e.g., contribution) is taken into consideration in the appraisal process, we might reach agreement regarding decisions on authorship more quickly than if multiple variables such as financing or effort are also considered.

A final argument in favor of distribution of authorship using desert is that it promotes the creation of knowledge. Recognition of research through authorship is at the center of the reward system of academia. This is not only reasonable, it is necessary. As noted by Lewis "It is not simply a question of pursuing excellence or of the rational utilization of resources; it is more basic and concerns the survival of universities as universities" (Lewis 1998, 206). Desert is particularly relevant in that it rewards deserving individuals who contribute to the survival of the university through their work. The broader institution of science has the responsibility to identify the more competent and productive individuals and to then distribute credit (e.g., status, research funds) to those who have the best chance of producing good research.

\section{Limitations of desert}

Distribution on the basis of deserved contribution is in no way a panacea and has limitations that, in certain cases, may render it unreasonable. Ranking may create an unhealthy level of competition among members and contribute to a hostile environment. As mentioned by Lewis, a meritocracy may create the "breeding of excessive competition" (Lewis 1998, p.202). Samuel Scheffler (2000) notes that desert is a very individualistic idea since it is tied to the actions of the individual, contrary to the more complete approach of social justice. While competition and individualism are realities that cannot be denied, it may be necessary to provide parameters as a counterbalance to also foster the productivity and synergy necessary in team collaborations. This will be discussed further in the section on collegiality.

As previously stated, the comparative assessment or quantification of contributions in relation to the project as a whole and relative to other team members is not a simple task, especially when the contributions are different in nature (e.g., technical and intellectual); it can be like comparing apples and oranges (Smith and Williams-Jones 2011). Open communication and information sharing are thus essential to arrive at an understanding of others' contributions. Yet, while this might be easy for a relatively small team, communication among larger teams (e.g., 10-100 individuals), especially when they are in different geographic areas, can be an insurmountable obstacle. Therefore, where practicable, and in cases where the quantity and nature of different contributions are sufficiently well understood, authorship distribution to deserving individuals on the basis of relative contribution is recommended.

\section{Fair Recognition}

When thinking of methods to fairly distribute authorship, the first normative theories that come to mind are theories of justice. As previously mentioned, in political philosophy these 
are applied to the establishment of fair institutions and are not specifically applicable in the academic context; however, this is not to say that fairness is irrelevant in an authorship distribution framework. In his book Inequality Reexamined, Amartya Sen (1992) explains how all normative theories of social justice in the last century - liberal, utilitarian, rights-based - rely on equality of certain elements, including: equal liberty, equal income, equality of primary rights, equality of treatment, equality of capabilities. The elements that should be distributed equally in such theories are usually those valued by all individuals. In many of the theories analyzed by Sen, equality seems to have some type of intrinsic moral significance (Feldman 2003).

However, as Shelly Kagan argues, equality can be a consequence of desert in that it is justified by the judgment that individuals deserve some sort of equality (Kagan 1999). The intrinsic moral value should be in desert, not in equality, because according to Kagan and certain desert theorists (e.g., Feldman 2003), equality is simply overrated. Egalitarianism cannot redress all injustices or put aside the broad range of distinctive genetic, physical, intellectual, or social traits of individuals; and it does not make all contexts fair. In some cases, the application of equality may paradoxically result in inequity. For example, paying everyone equal wages would not account for different skills, competencies and social value attributed to certain forms of work, nor would it address the fact that people have different obligations with regards to healthcare bills or child care, for example. Equal wages for all, without other targeted unequal distribution would likely create highly problematic and inequitable outcomes.

In many cases of authorship, perfect equality in distribution may lead to significant injustices. The implication that all team members deserve equal authorship is that they should all receive equal credit and have the same responsibility for the work. This distorts the reality of the research and writing processes. In disciplinary or multidisciplinary research teams, individuals reasonably make different contributions and are consequently responsible to differing degrees for different tasks. Equal distribution of authorship fails to acknowledge the level or amount of contribution, and it renders meaningless the assignment of responsibility within the research team that is central to research integrity. Individuals would ultimately be made less responsible and accountable for their work, and authorship distribution would be less meaningful. Equal authorship for all contributors is simply contrary to a quantification of contribution through authorship to differentiate the competent from incompetent, the productive from the unproductive and the deserving from the undeserving.

I do not think, however, that we should throw out the baby with the bathwater and omit fairness from ethical theory regarding authorship. Desert allows for the comparative assessment and ranking of individuals, and would benefit from a mechanism whereby each individual's contribution is evaluated in the same way. This equal treatment in the evaluation of contributions can promote greater fairness in authorship distribution. It is not necessary to choose between fairness and desert in the context of distribution of authorship in academia since these can and should coexist.

\section{Why use fair recognition of individual contribution as a reasonable principle?}

I will argue that fair recognition of contribution is a reasonable and necessary principle for authorship distribution for one very important reason: it is important in promoting and ensuring a certain level of impartiality and non-discrimination. To this effect, Sen writes: 
Need for some egalitarian formula in defending a theory indicates the significance widely attached to non-discrimination, which can be seen as being motivated by the idea that in absence of such a requirement a normative theory would be arbitrary and biased. There seems to be a recognition here of the need for impartiality in some form for the viability of a theory (Sen 2009, p.293).

Fairness and justice are brought to bear in finding non-arbitrary ways to distribute goods, merit, and resources. An evaluation mechanism that considers individual contributions in the same manner through a less biased lens could limit exploitation in authorship distribution while still promoting productivity in research. Although not every team member would be ranked equally, each individual would be treated fairly and measured in the same manner (through contribution).

Promotion of neutrality and non-arbitrariness are elements of justice that are already considered valuable in academia. However, as previously mentioned, there exist important power dynamics and ranking in the academic hierarchical structure designed to recognize knowledge and learning, e.g., professor-student, senior researcher-junior researcher. Yet, it is important that rank (seniority) not be a factor in authorship distribution; rather, the focus should be on the link between responsibility and authorship. This would reduce the impediment to entry-level advancement in academia since students or technical staff do occupy a lower position in the hierarchy. The emphasis on responsibility and not rank could reduce exploitation of the less experienced and duly recognize the contribution of senior researchers. Using rank as a criterion would only serve to encourage an even more hierarchical environment where power would be concentrated within an established elite, arguably threatening the scientific process.

\section{Limitations of fair recognition of individual contribution}

Although fair recognition seems like a reasonable criterion to help in the distribution of authorship it has important limitations, most of which are practical in nature. Even well intentioned individuals may introduce bias by unconsciously favoring personal or professional interests instead of considering each contribution in an equal fashion. In weighing contribution, an individual may unconsciously be influenced by association, friendship or reputation and thus attribute a higher standing in authorship than deserved. The literature on conflicts of interest shows that, regardless of good intentions, favoring personal or professional interests is often unconscious (Chugh, Bazerman, and Banaji 2005). Managing such interests within the team becomes all the more important.

Cases where individuals contribute equally and consequently deserve equal authorship can also present real challenges. As previously noted, alphabetical order of authorship can be considered to be unfair in that individuals with a last name that starts at the beginning of the alphabet will be favored, and those with a last name at or near the end disfavored. The alphabetical listing of names cannot reflect or represent equal contributions. As such, it would be important to provide a statement declaring that all individuals have contributed relatively equally. Individuals who work together often may change the authorship order in their next publication to share the opportunity to be named first and also add a declaration statement about equal contribution. The next section argues that transparency would represent or explain more accurately equal contributions and the associated responsibilities of team members. 


\section{Transparency}

The contributorship model has been considered as an effective method of increasing transparency (Smith 2012; Smith 1997; Tice 2005). By disclosing the specific tasks of individual contributors, it serves to clarify individual responsibility and accountability for various tasks. For example, a fictional contributor statement might read as follows: Mary Tomasson contributed to the project design and the writing of the article; Julie Madisson contributed to data collection, analysis and writing; and John James contributed to all steps of the research. However, while contributorship does provide additional detail and a measure of increased transparency, it does not necessarily reveal who deserves the most merit and responsibility. We do not know who made the greatest contribution, did the most work or deserves first author? While data collection is mentioned, it might represent $50 \%$ of the work in one project and only $5 \%$ of the work in another project. An individual may have made numerous small contributions in all phases of the research, which amount to relatively little work or work of lesser qualitative value, compared to that of other individuals who have completed only one task that represents for example, the bulk of the data collection and analysis in a data intensive project.

In order to better reflect the reality of the collaborative enterprise in authorship order, transparency can be applied through explanatory notes or disclaimers. According to Akhabue and Lautenback (2010), the disclaimer that more than one individual has contributed equally has become a more common practice in medical journals. Clarity as to the amount of work or the level of contribution benefits deserving individuals in their career advancement. As I will discuss further, transparency disclaimers would be useful in explaining other types of distribution than equal contribution.

\section{Why use transparency as a reasonable principle?}

Transparency can be considered a reasonable principle in the distribution of authorship for a number of reasons. First, it may limit confusion and misperception; declarations that state whether individuals are ranked in decreasing order of contribution, or are listed in alphabetical order and have all contributed equally, reveal more about the research. If we consider contribution to be linked to merit, responsibility and accountability through desert (as argued previously), transparency would further clarify and enhance these elements. If there is minimal or no transparency about authorship order, readers are left with their own individual assumptions which may be wrong.

Typically individuals tend to follow or be influenced by the prevailing norms of authorship within their respective discipline, field, or subfield. As a result, depending on their discipline, field or subfield, individuals may interpret authorship order differently. In a study of authors who published in the journal Radiology, authors were perceived to be named in decreasing order of credit in a majority of cases (70\%); this leaves little or no recognition or prestige for the last author (Slone 1996). However, in a survey of promotion committee members at American Medical Colleges regarding perceptions about authorship order, the first author in a three person byline was seen to have made the most contribution, while the last author's contribution on a five person's byline was perceived to be the greatest (Wren et al. 2007). These two studies from different disciplines illustrate very different perceptions concerning the significance or importance of the last author. I suggest that competing or 
differing perceptions will occur with greater frequency in multidisciplinary collaborations where there are no agreed upon norms or standards of authorship, making it all the more important to consider reasonable, ethical practices for multi-authored multidisciplinary research.

Transparency is also a reasonable and practical concept for authorship because it could facilitate more representative and flexible blending of various methods of authorship ordering that better reflect the contributions within diverse types of research teams. At first glance, one might suggest using Occam's razor and imposing a single method of authorship order to simplify the process (Resnik 1997). However, a single method and order of distribution is simply not realistic since there is no one model for team research. Teams are incredibly diverse in terms of size, discipline(s), organizational structure and epistemological background, and so a single approach to authorship distribution would likely lead to unfair situations. For example, a ranking order that fails to reflect the equal contribution of each member of a 5 person team would be unfair and misrepresent the work of the team members. In a large team of more than 500 individuals (e.g., in High-Energy physics), comparing the contributions of so many (besides maybe the first few or last authors) would be ridiculous; the difference between the 300th and 301 st author is of no significance. However, listing individuals in alphabetical order might seem equally unjust to the individual who did considerably more work than the rest of the team. To avoid these impracticalities and injustices, an approach that blends or borrows from different practices may be more useful and effective. For example, noting that that all authors except the first few and last have contributed equally may provide a more accurate and fairer way of distributing credit to members of a very large team. With sufficient transparency, we may blend or apply different orders, as long as they are not seen as unreasonable from the viewpoints of the team members (e.g., first three authors in order of contribution, the rest in alphabetical order, supported by a clear acknowledgement).

If all individuals agree to greater transparency and multiple or mixed authorship orders, there is a better chance that this will carry over to the reward system in the field and a greater variety or mixed types of evaluations. For example, researchers working in multidisciplinary research teams may reflect these diverse orders in their $\mathrm{CV}$, possibly with a section reserved for authorship in alphabetical order and another presenting authorship in ranked order. This would introduce greater precision and fairness in the assessment of authors engaged in multidisciplinary work and ultimately, would contribute to greater accuracy in the reward system.

Lastly, transparency may help foster fairness and ethical behavior since unfair or unethical behavior shuns discovery and publicity. For example, I mentioned that Biagioli (1999) explained how authorship has served to exploit certain individuals and minimize their contributions. This undermines the social dynamic which enhances team synergy and productivity. To reduce exploitation, authorship can and should reflect reality (as much as possible), and factor in both the social activity within a collective environment, as well as acknowledge individual elements. While ill-intentioned individuals can always hide wrongdoing, the promotion of continuous transparency as a principle will invite individuals to better communicate how contribution is distributed.

\section{Limitations of transparency}

It would be presumptuous to think that authorship order and transparent disclaimers would fully reflect all interactions involved in the conduct and publication of research; 
disclaimers can only tell part of the story. Individuals may be limited by journals that refuse to print or that minimize authorship disclaimers. Although I am unaware of journals openly banning disclaimers, the content and format requirements of journals can influence the communication of disclaimers. For example, a disclaimer written at the end of a paper (or even at the bottom of the cover page) in a very small font will draw less attention than one placed close to or directly underneath the authorship byline.

\section{Collegiality}

The notion of collegiality has not received much attention in the RCR literature, which is odd given the increasingly collaborative nature of research. When looking for a definition of collegiality in the university context, I came across certain organizational concepts for collegiality, especially in the fields of sociology (Lazega 2001; Crozier 1969; Smyth 1991; Waters 1989), management (Bess 1988) and higher education (Brett 1997; Nuttall 2012). These might have evolved to some extent as a result of Weber and Durkheim's debate on the sociology of organizations, where collegial models were discussed in detail. According to Waters (1989), Durkheim envisaged a normative function in an organizational form of collegiality where workers should share power in decision-making and thus promote a form of stability. Conversely, Weber saw collegiality as a negative element that would counter the bureaucratic, efficient and rapid decision-making, mainly in political affairs (Waters 1989). Regardless of whether it is welcome or not in an organization, shared decision-making is often considered as central to collegiality.

Since a research team may not exactly function as a highly structured organization but rather as a more organic, knowledge network of individuals, I have shied away from defining collegiality in strictly organizational terms. I will thus rely on the lesser known, but I think more fitting notion of collegiality developed by John Bartholomew Cavanagh (2010): "collegiality relates to the right to be heard, implying voice and democracy, as well as both the right and duty to influence processes and decisions for the common good through participation and consultation in the given social context" (Cavanagh 2010, p.1). This interpretation of collegiality fosters collaborative engagement, dialogue and shared knowledge, agreement, and research results. It is not an administrative procedure or an organizational protocol, but rather a continuous and more dynamic interaction that allows team members to address issues and achieve results collaboratively.

\section{Why use collegiality as a reasonable principle in authorship distribution?}

I use collegiality as a reasonable principle in authorship distribution to offset individualism and promote a productive context wherein a healthy level of competition can flourish through collaboration. Earlier, I highlighted a paradox in research: in a world where competition and individualism have traditionally dominated, there has been an emergence of multidisciplinary research teams which necessitate collaborative teamwork and open communication. But if individualism is rampant and the "survival of the fittest" attitude is overwhelming, teamwork and sharing of authorship becomes an almost impossible task. However, the quest for recognition in research and academia has also given rise to greater 
multidisciplinary collaboration, and productive teamwork has increasingly become the forum for innovation. As such, it is in most researchers' best interests to promote collegial relations (at least within their teams) while living with the reality of "publish or perish".

Individualism has received its share of criticism in various fields of research. Communitarian ethicists such as Alasdair MacIntyre (2013) or Micheal Walzer (1983) have criticized the individual ethics of much of liberal political philosophy, while Feminist ethics and Care ethics have been particularly important in countering the overemphasis of autonomy and individualism in bioethics (Friedman 2000). However, none of these perspectives have been applied to authorship or work in research integrity. As a result, the team as a collective entity and the collegial interrelations important to a cohesive, well-functioning group (including decision-making regarding authorship distribution) have rarely been addressed in normative theory.

A second reason to consider collegiality is that it can help in recognizing that group dynamics and the interdependence of individuals in collegial relationships can contribute to the important personal and professional growth of each member. Teamwork and collaboration are central topics of discussion in organizational psychology (Baker, Day, and Salas 2006; DeChurch and Mesmer-Magnus 2010; Deutsch 2003) and management (West 2012; Galegher, Kraut, and Egido 2014). The concept of synergy suggests that an organization of many people (in our case, a research team) has the potential to be much more than simply the sum of its parts (Katzenbach and Smith 1993). Kurt Lewin, a pioneer of organizational psychology and action research states that the group creates a "dynamical whole that has properties of its own" (Lewin 1948, p.60) In a collegial team, individuals can and should recognize that the team dynamic (mainly the relations between individuals) can support and enhance their individual contribution beyond what they could achieve alone. This awareness of others and the value of collaborative relationships could also have a positive influence on negotiations or agreement regarding authorship distribution.

Lastly, collegiality will facilitate the creation of fair procedures ${ }^{11}$ tailored to the team's context. As previously demonstrated, Scanlon's contractualism can help in identifying the wrong or unreasonable behaviors for distribution of authorship. However, research team members must agree upon one of the many available authorship distribution schemes, i.e., the one that is not only ethically reasonable but that also best applies to their situation. It is important that a collegial process of open discussion and negotiation engage all team members in arriving at satisfactory agreement. I submit that collegiality along with the principles previously discussed will indeed be useful to team members with differing perspectives and from various disciplines. A collegial environment would provide a more open forum for all members regardless of status, discipline, or country of origin; individuals would feel more comfortable in sharing knowledge, and in collaborating with less reservation or fear of exploitation. When the arrangement or agreement among members is reasonable as well as mutually beneficial, individuals might well temper (not suppress) their personal goals, and competitiveness, in order to benefit the collective, i.e., the team.

\footnotetext{
11 Since this paper focuses on theoretical elements of value in authorship distribution, I will not outline the procedures that are necessary in decision-making regarding authorship distribution since I consider it more of a practical consideration. A procedure will, however, be developed in my future work.
} 


\section{Limits of Collegiality}

Collegiality has some important practical limitations in team research. Understandably, it would be more feasible to implement a culture of collegiality in a small 5 person team than in large teams located in different geographic locations with different cultures, and social and professional norms. Greater effort is required for such large teams to make it possible for individuals to feel that they have a fair opportunity to be heard. As fictional (but realistic) examples, there may be team meetings in the different geographic areas where sub-teams exist; or, representatives may be elected to enable the representation of different individuals in the sub-groups. The notion of collegiality and the procedures appropriate to various types of group to distribute authorship will clearly need to be fleshed out in an eventual framework for it to be useful to practitioners.

\section{Summary}

The following table is a summary of the justifications and limitations of the conceptual principles proposed for ethical authorship distribution. It is important to note that while certain principles may be more important in certain contexts, principles suggested are not mutually exclusive and will most likely be more helpful when applied together. For example, in a large team setting individuals may agree to distribute authorship in decreasing order of contribution. They may consider that certain individuals deserve more credit and accountability then others. It is only through collegial conversation that individuals may arrive at such a decision. To limit discrimination, fair recognition is useful. Lastly, declarations may be used to give meaning to the order used. There will most likely be different processes that may be used to decide authorship and its order depending on the context of multidisciplinary research (type of team, size of team).

Table 1: Conceptual principles applied to authorship distribution in multidisciplinary teams

\begin{tabular}{|c|c|c|c|}
\hline Principles & $\begin{array}{c}\text { Interpretation in } \\
\text { authorship context }\end{array}$ & Justifications & Certain limitations \\
\hline Desert & $\begin{array}{l}\text { The worthiness that results } \\
\text { from contributing to a } \\
\text { research project. }\end{array}$ & $\begin{array}{l}\text { - Links merit and accountability } \\
\text { - Merit promotes innovation and } \\
\text { production } \\
\text { - Accountability promotes } \\
\text { responsible research } \\
\text { - Facilitates the evaluation of } \\
\text { contribution } \\
\text { - Appraisal helps in ordering } \\
\text { authorship. } \\
\text { - Promotes productivity and } \\
\text { excellence in research }\end{array}$ & $\begin{array}{l}\text { - May create excessive competition } \\
\text { - Difficulty in appraising } \\
\text { contributions of different natures } \\
\text { (e.g., technical or intellectual) }\end{array}$ \\
\hline Equality & $\begin{array}{l}\text { Each individual's } \\
\text { contribution is evaluated in } \\
\text { the same way through an } \\
\text { unbiased lens }\end{array}$ & $\begin{array}{l}\text { - Promotes less partial bias and } \\
\text { fairness. } \\
\text { - Reduces discrimination } \\
\text { - Mitigates disagreement within } \\
\text { teams }\end{array}$ & $\begin{array}{l}\text { - Unconscious bias due to conflict } \\
\text { of interest of evaluators } \\
\text { - Equal contribution not } \\
\text { represented through sequencing } \\
\text { order of authorship }\end{array}$ \\
\hline
\end{tabular}




\begin{tabular}{|c|c|c|c|}
\hline Transparency & $\begin{array}{l}\text { Declaration to explain the } \\
\text { meaning of authorship order }\end{array}$ & $\begin{array}{l}\text { - Clarity as to the nature and amount } \\
\text { of contribution } \\
\text { - Provides flexibility for different } \\
\text { orders to coexist } \\
\text { - May reduce incidence of unethical } \\
\text { or unfair behavior which shuns } \\
\text { discovery and publicity }\end{array}$ & $\begin{array}{l}\text { - Disclaimers are often brief and } \\
\text { can only represent part of } \\
\text { complex teamwork and } \\
\text { contributions } \\
\text { - Journal content or formatting } \\
\text { practices may undermine or } \\
\text { negate the utility of disclaimers }\end{array}$ \\
\hline Collegiality & $\begin{array}{l}\text { The right to be heard through } \\
\text { a democratic process and a } \\
\text { right to influence said } \\
\text { process for the common } \\
\text { good }\end{array}$ & $\begin{array}{l}\text { - Counterbalances individualism and } \\
\text { excessive competition } \\
\text { - Helps develop mutual recognition } \\
\text { of perspectives and practices } \\
\text { - Openness favors negotiation and } \\
\text { agreement in authorship decisions } \\
\text { - Contributes to team synergy } \\
\text { - Facilitates the creation of fair } \\
\text { evaluation procedures }\end{array}$ & $\begin{array}{l}\text { - Geographic distance } \\
\text { - Size of teams }\end{array}$ \\
\hline
\end{tabular}

\section{CONCLUSION}

At the outset of this conceptual analysis, I briefly described the context of authorship in academic research collaborations. I emphasized the critical importance of authorship in academia as it often defines the success of individuals in research; and I noted that the literature on authorship ethics has mainly discussed unethical practices such as guest, gift, and ghost authorship. I also discussed how the growing number of authors on papers creates general 'obfuscation' concerning who did the work, who is responsible and how authors are ordered. The norms and practices of authorship distribution and order vary considerably between fields of research and disciplines, raising particular challenges for individuals from multidisciplinary research teams who seek to publish together. Journal editor organizations such as ICMJE and WAME (and to a lesser extent, COPE) have taken the initiative and developed more specific authorship guidelines that are gaining increasing attention in the literature on authorship ethics. However, while they may prescribe exclusion and inclusion criteria for authorship in the biomedical or health sciences, the determination of authorship order (especially in multidisciplinary teams) remains particularly vague. Moreover, there are rarely any argued conceptual justifications to support the proposals in these guidelines. Without adequate, practical guidance that is based on sound theoretical grounds, individuals are left confused about the justifications for deciding authorship and its ordering.

I have argued that Thomas Scanlon's contractualism provides a useful theoretical foundation to justify principles that would contribute to the ethical distribution of authorship in multi-authored publications, and especially in multidisciplinary teams. Scanlon's theory states that the acts or behaviors in a given context are unethical if disallowed by principles that individuals would reasonably accept in a general agreement. In the specific context of authorship distribution in academia, contractualism allows us to justify a variety of principles such as desert, just recognition, transparency and collegiality. As Scanlon argues, the morality of an act must always be evaluated (deemed unreasonable or not) while also considering the circumstances (context) in which it takes place. Some of the principles conceptualized in this paper may have different interpretations depending on contextual specificities. For example, collegiality in a group of five individuals will no doubt differ from that in a team with 500 individuals spread around the world. 
As with any theoretical or conceptual approach, contractualism and the ensuing four principles I examined (i.e., desert, just recognition, transparency and collegiality) have their limitations, as has been acknowledged throughout this paper. Moreover, I have not presented a detailed working ethical framework, procedure or process that could be used in practice by multidisciplinary research teams, as this is beyond the scope of this paper. Empirical data regarding the specificities for multidisciplinary team research and their impact on authorship issues is needed in order to better understand the diversity of team practices and contexts. Along with the detailed theoretical foundations provided in this paper, such empirical data would provide the basis for the development of a practical framework to support ethical and nonarbitrary decision-making concerning authorship distribution in multidisciplinary team publications. The result would be a decision-making framework that is sufficiently flexible so as to be meaningful to users across diverse contexts (e.g., field, size, methods), while remaining ethically reasonable. 


\section{REFERENCES}

Abir-Am, Pnina G., and Clark A. Elliott. 2000. Commemorative Practices in Science: Historical Perspectives on the Politics of Collective Memory. University of Chicago Press.

Akhabue, Ehimare, and Ebbing Lautenbach. 2010. 'Equal' Contributions and Credit: An Emerging Trend in the Characterization of Authorship. Annals of Epidemiology 20 (11): 868-71.

Allen, Liz, Amy Brand, Jo Scott, Micah Altman, and Marjorie Hlava. 2014. "Credit Where Credit Is Due." Nature 508: 312-13.

Anstey, Alex. 2014. “Authorship Issues: Grizzles, Guests and Ghosts.” British Journal of Dermatology 170 (6): 1209-10.

Baethge, C. 2008. Publish Together or Perish: The Increasing Number of Authors per Article in Academic Journals Is the Consequence of a Changing Scientific Culture. Some Researchers Define Authorship Quite Loosely. Deutsches Arzteblatt International 105: 380.

Baker, David P., Rachel Day, and Eduardo Salas. 2006. "Teamwork as an Essential Component of High-Reliability Organizations." Health Services Research 41 (4p2): 1576-98.

Barkovic, Drazen. 2010. Challenges Of Interdisciplinary Research. Interdisciplinary Management Research 6: 951-60. http://ideas.repec.org/a/osi/journl/v6y2010p951-960.html. Beasley, Craig J. 2005. Publish or Perish. The Leading Edge 24 (9): 872-872.

Bennett, DM, and DMD Taylor. 2003. Unethical Practices in Authorship of Scientific Papers. Emergency Medicine 15: 263-70.

Bess, James L. 1988. Collegiality and Bureaucracy in the Modern University: The Influence of Information and Power on Decision Making Structures. ERIC. http://www.eric.ed.gov/ERICWebPortal/recordDetail?accno=ED291318.

Biagioli, M. 1999. Aporias of Scientific Authorship: Credit and Responsibility in Contemporary Biomedicine. The Science Studies Reader, Edited by M. Biagioli. New York: Routledge.

Brett, Judith. 1997. "Competition and Collegiality." Australian Universities' Review 40 (2): 1922.

Cavanagh, John Bartholomew. 2010. Managing Collegiality: The Discourse of Collegiality in Scottish School Leadership. University of Glasgow. http://theses.gla.ac.uk/2254/.

Chugh, Dolly, Max Bazerman, and Mahzarin Banaji. 2005. Bounded Ethicality as a Psychological Barrier to Recognizing Conflicts of Interest. In Conflicts of Interest: Challenges and Solutions in Business, Law, Medicine, and Public Policy, p.75. Cambridge University Press.

Clapham, Phil. 2005. Publish or Perish. BioScience 55 (5): 390.

Clement, T. Prabhakar. 2013. Authorship Matrix: A Rational Approach to Quantify Individual Contributions and Responsibilities in Multi-Author Scientific Articles. Science and Engineering Ethics. doi:10.1007/s11948-013-9454-3. http://link.springer.com/content/pdf/10.1007\%2Fs11948-013-9454-3.pdf.

Committee on Publication Ethics. 2013. Committee on Publication Ethics: COPE ; Raising the Quality of Academic Journals. Accessed June 21. http://publicationethics.org/.

Comstock, Gary. 2013. Research Ethics: A Philosophical Guide to the Responsible Conduct of Research. Cambridge University Press.

COPE. 2011. Code of Conduct; Committee on Publication Ethics. http://publicationethics.org/resources/code-conduct.

Cronin, B. 2005. The Hand of Science: Academic Writing and Its Rewards. Scarecrow Pr. Cronin, Blaise. 2001. "Hyperauthorship: A Postmodern Perversion or Evidence of a Structural 
Shift in Scholarly Communication Practices?" Journal of the American Society for Information Science and Technology 52 (7): 558-69.

Crozier, Michel. 1969. The Bureaucratic Phenomenon. Vol. 280. Transaction Publishers. Daniels, Norman. 1990. "Equality of What: Welfare, Resources, or Capabilities?" Philosophy and Phenomenological Research 50 (October): 273-96. doi:10.2307/2108044.

_ 2000. "Accountability for Reasonableness: Establishing a Fair Process for Priority Setting Is Easier than Agreeing on Principles [Editorial]." British Medical Journal 321: 1300-1301.

Darwell, Stephen. 2003. Contractarianism/Contractualism. Vol. 8. Wiley-Blackwell.

De Chadarevian, Soraya. 2002. Designs for Life: Molecular Biology After World War II.

Cambridge, UK: Cambridge University Press.

DeChurch, Leslie A., and Jessica R. Mesmer-Magnus. 2010. "The Cognitive Underpinnings of

Effective Teamwork: A Meta-Analysis.” Journal of Applied Psychology 95 (1): 32.

Dench, Geoff. 2006. The Rise and Rise of Meritocracy. Wiley-Blackwell.

De Rond, M., and A.N. Miller. 2005. Publish or Perish. Journal of Management Inquiry 14: 321.

Deutsch, Morton. 2003. "Cooperation and Conflict: A Personal Perspective on the History of the

Social Psychological Study of Conflict Resolution." International Handbook of

Organizational Teamwork and Cooperative Working, 9-43.

Endersby, James W. 1996. Collaborative Research in the Social Sciences: Multiple Authorship and Publication Credit. Social Science Quarterly 77 (2): 375-92.

http://cat.inist.fr/?aModele=afficheN\&cpsidt=2868041.

Feinberg, Joel. 1974. Doing and Deserving : Essays in the Theory of Responsibility. Princeton,

NJ: Princeton University Press.

Feldman, Fred. 1995. Desert: Reconsideration of Some Received Wisdom. Mind 104 (413): $63-$ 77.

2003. Return to Twin Peaks: On the Intrinsic Moral Significance of Equality. In Desert and Justice, 145-68. Clarendon Press.

Friedman, M. 2000. Feminism in Ethics: Conceptions of Autonomy. The Cambridge Companion to Feminism in Philosophy: 205-24.

Galegher, Jolene, Robert E. Kraut, and Carmen Egido. 2014. Intellectual Teamwork: Social and Technological Foundations of Cooperative Work. Psychology Press.

Giddens, Anthony. 1986. The Constitution of Society: Outline of the Theory of Structuration. University of California Press.

Gingras, Yves, and Éric Archambault. 2006. Canadian Collaboration Networks: A Comparative Analysis of the Natural Sciences, Social Sciences and the Humanities. Scientometrics 68 (3): 519-33.

GUSTO. 1993. An International Randomized Trial Comparing Four Thrombolytic Strategies for Acute Myocardial Infarction. New England Journal of Medicine 329: 673-82.

Hooker, Brad. 2002. Contractualism, Spare Wheel, Aggregation. Critical Review of International Social and Political Philosophy 5 (2): 53-76.

Hughes, Jonathan, and Stephen De Wijze. 2001. Moral Contractualism Comes of Age. Res Publica 7 (2): 189-96.

ICMJE. 2008. Uniform Requirements for Manuscripts Submitted to Biomedical Journals: Ethical Considerations in the Conduct and Reporting of Research: Authorship and Contributorship. http://www.icmje.org/ethical_1author.html.

- 2014. "Recommendations for the Conduct, Reporting, Editing, and Publication of Scholarly Work in Medical Journals.” http://www.icmje.org/icmje-recommendations.pdf. 
International Committee of Medical Journal Editors. 2014. ICMJE: Uniform Requirements for Manuscripts Submitted to Biomedical Journals. Accessed June 21. http://www.icmje.org/. Kagan, Shelly. 1999. Equality and Desert. In What Do We Deserve, 298-314.

Kant, Immanual. 1785. Groundwork of the Metaphysics of Morals. Lanham: Start Publishing LLC.

Katzenbach, Jon R., and Douglas K. Smith. 1993. The Discipline of Teams. Harvard Business Press.

Katz, JS, and BR Martin. 1997. "What Is Research Collaboration?” Research Policy 26: 1-18.

Kukla, Rebecca. 2012. “'Author TBD': Radical Collaboration in Contemporary Biomedical Research." Philosophy of Science 79 (5): 845-58.

Kunst, F., N. Ogasawara, I. Moszer, A. M. Albertini, G. Alloni, V. Azevedo, M. G. Bertero, et al. 1997. The Complete Genome Sequence of the Gram-Positive Bacterium Bacillus Subtilis. Nature 390: 249-56.

LaFollette, Marcel Chotkowski. 1992. Stealing Into Print: Fraud, Plagiarism, and Misconduct in Scientific Publishing. University of California Press.

Lambert-Chan, Marie. 2013. Des Étudiants Réclament Une Réflexion Autour Du Corédaction Scientifique. University Affairs/Affaires Universitaires, October 16.

http://www.affairesuniversitaires.ca/des-etudiants-reclament-une-reflexion-autour-du-coautorat-scientifique.aspx.

Latour, Bruno. 1989. “La Littérature Scientifique.” In La Science En Action; Introduction À La Sociologie Des Sciences, 59-111. Paris: Gallimard.

Latour, Bruno, and S. Woolgar. 1979. Laboratory Life: The Social Construction of Scientific Facts. Beverly Hills and London: Sage.

Lazega, Emmanuel. 2001. The Collegial Phenomenon: The Social Mechanisms of Cooperation Among Peers in a Corporate Law Partnership. Oxford University Press.

Lewin, Kurt. 1948. "Experiments in Social Space.” In Resolving Social Conflicts: Selected Papers on Group Dynamics, 59-67. London: Harper and Row.

Lewis, Lionel S. 1998. Scaling the Ivory Tower: Merit \& Its Limits in Academic Careers. Transaction Publishers.

Lexchin, Joel, Lisa A. Bero, Benjamin Djulbegovic, and Otavio Clark. 2003. "Pharmaceutical Industry Sponsorship and Research Outcome and Quality: Systematic Review.” Bmj 326 (7400): 1167-70.

Louis, KS, JM Holdsworth, MS Anderson, and EG Campbell. 2008. "Everyday Ethics in Research: Translating Authorship Guidelines into Practice in the Bench Sciences." The Journal of Higher Education 79: 88-112.

MacIntyre, Alasdair. 2013. After Virtue. Black.

Maddox, Brenda. 2003. "The Double Helix and the "Wronged Heroine." Nature 421 (6921): 407-8.

Matías-Guiu, J., and R. García-Ramos. 2011. "Ghost-Authors, Improvement Article Communication, and Medical Publications." Neurología (English Edition) 26 (5): 257-61.

Matravers, Matt. 2003. Scanlon and Contractualism. Routledge.

McClellan, James Edward, and Harold Dorn. 1999. "Chapter 18. Applied Science and Technology Today.” In Science and Technology in World History: An Introduction, 355-70. Baltimore, Maryland: John Hopkins University Press.

Miller, David. 2003. "Comparative and Noncomparative Desert." In Desert and Justice, 25-44. Oxford: Clarendon Press.

Mill, John Stuart. 1870. Utilitarianism. Longmans, Green. 
Moffatt, B. 2011. "Responsible Authorship: Why Researchers Must Forgo Honorary Authorship." Accountability in Research 18 (2): 76-90.

Moffatt, Barton, and Carl Elliott. 2007. "Ghost Marketing: Pharmaceutical Companies and Ghostwritten Journal Articles." Perspectives in Biology and Medicine 50 (1): 18-31.

Mowatt, Graham, Liz Shirran, Jeremy M. Grimshaw, Drummond Rennie, Annette Flanagin, Veronica Yank, Graeme MacLennan, Peter C. Gøtzsche, and Lisa A. Bero. 2002. "Prevalence of Honorary and Ghost Authorship in Cochrane Reviews." Jama 287 (21): 2769-71.

Mullen $=$ Kochan $=$ Kochan $=$ Mullan. 2001. "Issues of Collaborative Authorship in Higher Education." The Educational Forum 65 (2): 128-35.

Nuttall, Chad C. 2012. "Everyday Tensions Between Collegiality and Managerialism: Administrators at a Canadian Research University." University of Toronto.

Olsaretti, Serena. 2003. "Introduction." In Desert and Justice. Oxford: Clarendon Press.

Onwude, J L, A Staines, and R J Lilford. 1993. "Multiple Author Trend Worst in Medicine." BMJ : British Medical Journal 306 (6888): 1345.

Pojman, Louis. 1999. “Merit: Why Do We Value It?” Journal of Social Philosophy 30 (1): 83102.

Pojman, Louis P., and Owen McLeod. 1999. What Do We Deserve?: A Reader on Justice and Desert. Oxford University Press New York.

Rawls, John. 1971. A Theory of Justice. Cambridge, Mass.: Belknap Press of Harvard University Press.

Rennie, D., and A. Flanagin. 1994. "Authorship! Authorship!” The Journal of the American Medical Association 271: 469.

Rennie, Drummond. 2001. "Who Did What? Authorship and Contribution in 2001." Muscle \& Nerve 24 (10): 1274-77.

Rennie, D, V Yank, and L Emanuel. 1997. "When Authorship Fails. A Proposal to Make Contributors Accountable." The Journal of the American Medical Association 278 (7): 57985.

Resnik, David. 1997. “A Proposal for a New System of Credit Allocation in Science.” Science and Engineering Ethics 3 (3): 237-43.

Ross, J. S., K. P. Hill, D. S. Egilman, and H. M. Krumholz. 2008. "Guest Authorship and Ghostwriting in Publications Related to Rofecoxib." The Journal of the American Medical Association 299 (15): 1800-1812.

Rousseau, Jean-Jacques. 1762. The Social Contract. 1998 edition. Wordsworth Editions.

Scanlon, Thomas M. 1998. What We Owe to Each Other. Harvard University Press.

Scheffler, Samuel. 2000. "Justice and Desert in Liberal Theory." California Law Review 88: 965. Sen, A. 2009. The Idea of Justice. Belknap Press.

Sen, Amartya. 1992. Inequality Reexamined. Oxford University Press.

Shamoo, Adil E., and David B. Resnik. 2009. Responsible Conduct of Research. New York: Oxford University Press.

Sismondo, Sergio. 2009. "Ghosts in the Machine Publication Planning in the Medical Sciences." Social Studies of Science 39 (2): 171-98.

Slone, R. M. 1996. "Coauthors' Contributions to Major Papers Published in the AJR: Frequency of Undeserved Coauthorship." American Journal of Roentgenology 167 (3): 571-79.

Smith, E., and B. Williams-Jones. 2011. "Authorship and Responsibility in Health Sciences Research: A Review of Procedures for Fairly Allocating Authorship in Multi-Author Studies." Science and Engineering Ethics 18 (2): 1-14. 
Smith, R. 1997. “Authorship Is Dying: Long Live Contributorship.” BMJ 315 (7110): 696. . 2012. "Let's Simply Scrap Authorship and Move to Contributorship." BMJ 344. http://www.bmj.com/content/344/bmj.e157.short?rss=1.

Smyth, John. 1991. "International Perspectives on Teacher Collegiality: A Labour Process Discussion Based on the Concept of Teachers' Work." British Journal of Sociology of Education 12 (3): 325-46.

Street, Jackie M., Wendy A. Rogers, Mark Israel, and Annette J. Braunack-Mayer. 2010. "Credit Where Credit Is Due? Regulation, Research Integrity and the Attribution of Authorship in the Health Sciences." Social Science \& Medicine 70 (9): 1458-65.

Sulmasy, Daniel P., and Jeremy Sugarman. 2010. "The Many Methods of Medical Ethics (Or, Thirteen Ways of Looking at a Black Bird)." In Methods in Medical Ethics, 2nd ed., 3-20. US: Georgetown University Press.

Tice, Pamela Paradis. 2005. "Contributorship: Promoting Greater Authorship Integrity." AMWA Journal 20: 7-9.

Tsao, M.D., and M.D. Roberts. 2009. “Authorship in Scholarly Manuscripts: Practical Considerations for Resident and Early Career Physicians.” Academic Psychiatry 33 (1): 7679.

Van Dalen, Hendrik P., and Kène Henkens. 2012. "Intended and Unintended Consequences of a Publish-or-Perish Culture: A Worldwide Survey." Journal of the American Society for Information Science and Technology 63 (7): 1282-93.

Van Praag, CM, and BMS Van Praag. 2008. "The Benefits of Being Economics Professor A (Rather than Z)." Economica 75: 782-96.

Wager, Elizabeth. 2007. "Do Medical Journals Provide Clear and Consistent Guidelines on Authorship?" Medscape General Medicine 9 (3): 16.

—. 2009. "Recognition, Reward and Responsibility: Why the Authorship of Scientific Papers Matters.” Maturitas 62: 109-12.

Walzer, Micheal. 1983. Spheres of Justice: A Defense of Pluralism and Equality. Basic Books.

WAME. 2013a. "Welcome to the World Association of Medical Editors - World Association of Medical Editors." Accessed June 21. http://www.wame.org/.

—. 2013b. "Policy Statements — World Association of Medical Editors." Accessed June 21. http://www.wame.org/resources/policies\#authorship.

Waters, Malcolm. 1989. "Collegiality, Bureaucratization, and Professionalization: A Weberian Analysis.” American Journal of Sociology 94 (5): 945-72.

Watson, James D, and Francis H Crick. 1953. "Molecular Structure of Nucleic Acids; a Structure for Deoxyribose Nucleic Acid." Nature 171 (4356): 737-38.

Weeks, William B, Amy E Wallace, and B.C.Surott Kimberly. 2004. "Changes in Authorship Patterns in Prestigious US Medical Journals.” Social Science \& Medicine 59 (9): 1949-54. doi:10.1016/j.socscimed.2004.02.029.

West, Michael A. 2012. Effective Teamwork: Practical Lessons from Organizational Research. John Wiley \& Sons.

Wislar, J. S., A. Flanagin, P. B. Fontanarosa, and C. D. DeAngelis. 2011. "Honorary and Ghost Authorship in High Impact Biomedical Journals: A Cross Sectional Survey." BMJ 343 (oct25 1): d6128-d6128.

Wren, JD, KZ Kozak, KR Johnson, SJ Deakyne, LM Schilling, and RP Dellavalle. 2007. "The Write Position. A Survey of Perceived Contributions to Papers Based on Byline Position and Number of Authors." EMBO Reports 8: 988.

Young, Michael. 1958. The Rise Ofthe Meritocracy. Penguin Books. 
Article in accepted in Kennedy Institute of Ethics Journal (2015) 